\title{
Inhibition of the invasion and migration of renal carcinoma 786-o-si3 cells in vitro and in vivo by Koelreuteria formosana extract
}

\author{
CHIN-YIN LIN ${ }^{1}$, PEI-NI CHEN ${ }^{1,2}$, LI-SUNG HSU ${ }^{1,2}$, DONG YIH KUO ${ }^{3}$, SHU-CHEN CHU $^{4}$ and YIH-SHOU HSIEH ${ }^{1,2}$ \\ ${ }^{1}$ Institute of Biochemistry and Biotechnology, ${ }^{2}$ Clinical Laboratory and ${ }^{3}$ Department of Physiology, \\ Chung Shan Medical University, Taichung 40201; ${ }^{4}$ Institute and Department of Food Science, \\ Central Taiwan University of Science and Technology, Taichung 40601, Taiwan, R.O.C.
}

Received February 26, 2014; Accepted July 25, 2014

DOI: $10.3892 / \mathrm{mmr} .2014 .2587$

\begin{abstract}
Koelreuteria formosana ethanolic extract (KFEE) is obtained from natural plants that are endemic to Taiwan. In a previous study, it was demonstrated that KFEE inhibited low-density lipoprotein (LDL) and prevented oxidized LDL-induced apoptosis in endothelial cells. In the present study, KFEE was shown to inhibit the invasion and migration of 786-O-SI3 renal cell carcinoma (RCC) cells while not exhibiting any cytotoxic effects. 786-O-SI3 cells were treated with KFEE at numerous concentrations of $\leq 100 \mu \mathrm{g} / \mathrm{ml}$ for $24 \mathrm{~h}$. In order to examine the effects of KFEE, cells were then subjected to a series of assays for cell viability (MTT), wound healing migration, cell invasion and migration, gelatin zymography, casein zymography and immunofluorescence, as well as western blot analysis. KFEE was shown to decrease levels of matrix metalloproteinase-2, phosphorylated (p-)focal adhesion kinase Try925, p-paxillin Ser178, p-mitogen-activated protein kinase kinase $1 / 2$, p-myosin light chain and p-extracellular signal-regulated kinase $1 / 2$ in $786-0-$ SI 3 cells. Reduction of lung metastases was observed in KFEE-treated mice compared with vehicle-treated control mice. KFEE inhibited the invasion of RCC cells and may have the potential for use as a chemopreventive agent against RCC metastasis.
\end{abstract}

Correspondence to: Professor Yih-Shou Hsieh, Institute of Biochemistry and Biotechnology, Chung Shan Medical University, No. 110, Sec. 1, Jianguo N. Rd, Taichung 40201, Taiwan, R.O.C.

E-mail: csmcysh@csmu.edu.tw

Professor Shu-Chen Chu, Institute and Department of Food Science, Central Taiwan University of Science and Technology, Taichung 40601, Taiwan, R.O.C.

E-mail: scchu@ctust.edu.tw

Key words: Koelreuteria formosana, matrix metalloproteinase, urinary-type plasminogen activator, renal cell carcinoma, metastasis

\section{Introduction}

The most common type of kidney malignancy is renal cell carcinoma (RCC), which accounts for $3 \%$ of tumors in adults (1). Only $2 \%$ of the cases of RCC are associated with inherited gene mutations. $70-75 \%$ of renal cancers are clear cell carcinomas, a type of cancer that is traditionally resistant to chemo- or radiotherapy (2). Therefore, surgical resection is the preferred treatment option for patients with stage I-IV, localized primary tumors. However, the effectiveness of surgery as a cure for RCC is highly dependent on the stage and grade of the disease. Approximately $25 \%$ of patients present with advanced disease, including locally invasive and metastatic $\mathrm{RCC}$, the median survival time for which is 13 months $(3,4)$. Patients with locally advanced or metastatic RCC are generally offered treatment options; however, chemotherapy alone has shown low response rates $(5,6)$. Immunomodulatory therapies with various cytokines have been investigated in patients with metastatic RCC; two of these agents, interleukin-2 and interferon-a, demonstrated reproducible antitumor effects with objective response rates of $15-31 \%$. However, not all patients with metastatic RCC showed improvements with these treatments (7). Prior to 2005, high-dose interleukin-2 was the only Food and Drug Administration-approved treatment for RCC (8). Overall, metastatic RCC has a low survival rate and $20-30 \%$ of patients with early stage RCC at the time of nephrectomy having tumor metastasis and a median relapse time following nephrectomy of 15-18 months $(7,9)$.

Guan-Jen-Huang extract has been shown to have a synergistic effect on chemotherapy-induced apoptosis; moreover, it has been reported to decrease cell adhesion, migration and invasion (10). Mouse xenograft experiments have shown that treatment with the aqueous extract of Paeonia suffruticosa significantly inhibited tumor growth and pulmonary metastasis of RCC cells (11). Allergen-free Rhus verniciflua stokes extract may be a promising approach for the treatment of unresectable multiple metastases (12).

Koelreuteria formosana, commonly known as Chinese rain tree, is a deciduous tree native to Taiwan and 15-20 m in height. Koelreuteria formosana ethanolic extract (KFEE) was reported to have a suppressive effect on 
oxidized low-density lipoprotein (oxLDL)-mediated vascular endothelial dysfunction(13). K. formosana has been found to contain protein-tyrosine kinase (PTK) inhibitors, including anthraquinone, stilbene and flavonoids (e.g. galangin, morin, myricetin and apigenin) (14). It is therefore thought that $K$. formosana may have potential as an anticancer drug (15). Flavonol, galloylrhamnoside, lignin and glycoside can be found in the leaves of $K$. formosana (16) and its ethanolic extract contains kaempferol and quercetin, which may have potential PTK-inhibitory activity. The importance of PTK in anticancer treatment is due to its regulatory effect on cell proliferation (17). K. formosana contains the cyclolignans austrobailignan-1 and -2 (18). The extracted components of $K$. formosana have been shown to have a more powerful antioxidant capability than xanthine oxidase, lipoxygenase and tyrosinase (19). In a previous study, it was demonstrated that KFEE inhibited human LDL in vitro and prevented oxLDL-induced apoptosis in human umbilical vein endothelial cells (20). Studies on the functions of $K$. formosana have mainly concentrated on its antiproliferative or antioxidant activity. However, the effect of this plant on tumor cell migration and invasion has remained elusive. The aims of the present study were to examine the effects of $K$. formosana on RCC metastasis in vivo and on cell invasion, migration, motility and proteinase expression in vitro.

\section{Materials and methods}

Preparation of KFEE. K. formosana branches, following the shedding of their leaves, were purchased from local herb stores in Taichung, Taiwan. K. formosana peduncle extracts were prepared by initial condensation, followed by lyophilization, as previously described (13). In brief, $100 \mathrm{~g}$ air-dried branch was boiled with $50 \%$ ethanol at $70^{\circ} \mathrm{C}$ for $24 \mathrm{~h}$. The solvent was removed from the combined extract with a vacuum rotary evaporator. The filtrate was then lyophilized and stored at $-20^{\circ} \mathrm{C}$.

Total phenolic contents. The total phenolic content was measured by photometric assay using a Folin-Ciocalteu reagent (Fluka, Buchs, Switzerland) (19). Folin-Ciocalteu reagent was added to each sample and sodium carbonate (Sigma, St. Louis, MO, USA) was added. The specific absorbance was measured immediately at $760 \mathrm{~nm}$ using a spectrophotometer (Thermo Biomate 5; Thermo Electron Corporation, San Jose, CA). Gallic acid (Sigma) was used as a standard phenolic compound for the calibration curve $(y=0.7758 x+0.0582$, $\mathrm{R} 2=0.9982$ ). Total phenolic content was expressed as milligrams of gallic acid equivalents per gram of dry weight of plant (mg GA/g DW).

High-performance liquid chromatography (HPLC) analysis. HPLC analysis (Waters 600 with a 2998 photodiode array detector; Waters Corp., Milford, MA, USA) was conducted with a LiChroCART RP-18 reversed phase column $(200 \times 4 \mathrm{mM}$; $5 \mu \mathrm{m}$ Merck KGaA, Parmstadt, Germany), the mobile phase consisted of water/acetic acid $(0.05 \%, \mathrm{v} / \mathrm{v})$ (solvent A) and acetic acid/water/acetonitrile $(0.05 \%, \mathrm{v} / \mathrm{v}$; Sigma) (solvent B). Elution was carried out in a programmed gradient elution as follows: $0-30 \mathrm{~min}$ with $0-100 \% \mathrm{~B}$.
Establishment of xenograft-derived 786-O cell lines. To establish the first generation of xenograft-derived 786-O cell lines, 786-O cells were injected subcutaneously into the dorsal flank of five-week-old nude BALB/c nu/nu mice. The size of each tumor was measured as described previously (21). Solid tissue from the tumor was then mechanically and enzymatically disaggregated using collagenase $(0.7 \mathrm{mg} / \mathrm{ml})$ in serum-free medium (Sigma) into a single-cell suspension and was designated as 786-O-SI1. A second-generation xenograft-derived 786-O cell line was established following an identical protocol, using cells from the 786-O-SI1 cell tumor; this single-cell suspension was designated as 786-O-SI2. The third-generation xenograft-derived 786-O cell line was established from the tumor produced by the 786-O-SI 2 cells and was designated as $786-\mathrm{O}-\mathrm{SI} 3$.

Cell culture and KFEE treatment. RCC cell line 786-O-SI3 and human kidney-2 (HK-2; a human proximal tubule epithelial cell line) cells were purchased from the Food Industry Research and Development Institute (Hsinchu, Taiwan). The RCC cell line 786-O-SI3 was cultured in RPMI 1640 medium (Gibco-BRL, St. Louis, MO, USA) supplemented with $10 \%$ fetal calf serum, $2 \mathrm{mM}$ L-glutamine, $100 \mathrm{mg} / \mathrm{ml}$ streptomycin and 100 units/ml penicillin (Sigma). HK-2 was cultured in a 1:1 mixture of Dulbecco's modified Eagle's medium and Ham's F12 medium (Gibco-BRL) containing 10\% fetal bovine serum (FBS; Gibco-BRL). The cell cultures were maintained at $37^{\circ} \mathrm{C}$ in a humidified atmosphere of $5 \% \mathrm{CO}_{2}$. KFEE treatment was added to the culture medium at different concentrations $(25,50,75$ and $100 \mu \mathrm{g} / \mathrm{ml})$ and was incubated with cells for $24 \mathrm{~h}$. DMSO (final concentration $0.1 \%$ ) without KFEE was used as a blank reagent.

Determination of cell viability (MTT assay). To evaluate the cytotoxicity of KFEE, cell viability was determined using an MTT colorimetric assay (Sigma) (22). Cells were seeded in 24 -well plates at a density of $3 \times 10^{4}$ cells/well and were treated with concentrations of KFEE of $0-100 \mu \mathrm{g} / \mathrm{ml}$ at $37^{\circ} \mathrm{C}$ for $24 \mathrm{~h}$. Following incubation for $24 \mathrm{~h}$, the media were removed and the cells were washed with phosphate-buffered saline (PBS; Sigma). The medium was then changed and the cells were incubated with $20 \mathrm{ml}$ MTT $(5 \mathrm{mg} / \mathrm{ml})$ for $4 \mathrm{~h}$. The viable cell number/dish was directly proportional to formazan production, which, following solubilization with isopropanol (Sigma), was measured by a Hitachi U-1900 spectrophotometer (Hitachi, Tokyo, Japan) at $563 \mathrm{~nm}$.

Wound healing migration assay. Wounds were introduced to the confluent monolayer of cells with culture-inserts (Ibidi $\mathrm{GmbH}$, Martinsried, Germany) to create a cleared line. The medium was removed and replaced with RPMI 1640 medium containing $1 \%$ FBS, and KFEE was then added. The cells were incubated at $37^{\circ} \mathrm{C}$ and cell migration into the wound area was documented at 0,6 and $24 \mathrm{~h}$ by a microscope (CKX 41 : Olympus, Tokyo, Japan).

Cell invasion and migration assays. The 786-O-SI3 cells were pre-treated with KFEE at indicated concentrations $(0,25,50$, 75 and $100 \mu \mathrm{g} / \mathrm{ml}$ ) for $24 \mathrm{~h}$. The cells were then harvested and seeded in a Boyden chamber (Neuro Probe, Cabin 
John, MD, USA) with $10^{4}$ cells/well in serum-free medium and were incubated at $37^{\circ} \mathrm{C}$ for $12 \mathrm{~h}$. For the invasion assay, $10 \mathrm{ml}$ Matrigel ${ }^{\circledR}(25 \mathrm{mg} / 50 \mathrm{ml}$; BD Biosciences, Bedford, MA, USA) was applied to polycarbonate membrane filters (Neuro Probe, Cabin John, MD, USA) with a pore size of $8 \mathrm{mM}$ and the bottom chamber of the apparatus contained a standard medium. Following incubation, the filters were air dried in a laminar flow hood for $5 \mathrm{~h}$. The invaded cells were fixed with methanol and stained with Giemsa (Sigma). Cell numbers were counted with a light microscope (CKX41; Olympus) and the migration assay was carried out as described for the invasion assay, with no coating of Matrigel (23).

Determination of matrix melloproteinase (MMP)-2 and urinary-type plasminogen activator (u-PA) by zymography. The activities of MMP-2 and MMP-9 on the condition medium were measured by gelatin-zymogram protease assays, as previously described (24). Samples were prepared with a standard SDS gel-loading buffer containing 0.01\% SDS without $\beta$-mercaptoethanol and were not boiled prior to loading. The prepared samples were then subjected to 8\% SDS-PAGE (0.75-mm; acrylamide/bis-acrylamide 30/1.2; containing 0.1\% gelatin; Sigma).Electrophoresis was performed at $150 \mathrm{~V}$ in an OWL P-1 apparatus (Alpha Multiservices, Inc., Contoe, TX, USA) for $3 \mathrm{~h}$. Following electrophoresis, the gels were washed twice with $100 \mathrm{ml}$ distilled water containing $2 \%$ Triton X-100 (Sigma) on a gyratory shaker at room temperature for $30 \mathrm{~min}$ to remove the SDS. The gel was then incubated in $100 \mathrm{ml}$ reaction buffer $(40 \mathrm{mM}$ Tris- $\mathrm{HCl}, \mathrm{pH} 8.0$, $10 \mathrm{mM} \mathrm{CaCl}_{2}, 0.02 \% \mathrm{NaN}_{3}$; Sigma) at $37^{\circ} \mathrm{C}$ for $12 \mathrm{~h}$, stained with Coomassie brilliant blue R-250 and de-stained with methanol/acetic acid/water (50/75/875, v/v/v; Sigma). u-PA activity was visualized as previously described (24). $2 \% \mathrm{w} / \mathrm{v}$ casein and $20 \mathrm{mg} / \mathrm{ml}$ plasminogen (Sigma) were added to $8 \%$ SDS-PAGE gels. Electrophoresis and zymography were then performed for gelatin zymography.

Immunofluorescence assay. 786-O-SI3 cells grown on glass coverslips were fixed in $4 \%$ paraformaldehyde (Sigma) at room temperature for $12 \mathrm{~min}$. Following washing in PBS, the cells were blocked and permeabilized in PBS containing 4\% bovine serum albumin and $0.1 \%$ Triton X-100 at room temperature for $90 \mathrm{~min}$. Filamentous actin was detected by incubating coverslips with rhodamine-conjugated phalloidin (1:200) at $4^{\circ} \mathrm{C}$ overnight and nuclei were counterstained with DAPI (Sigma) at room temperature for $1 \mathrm{~h}$. The cells were viewed and photographed with a ZEISS Axioskop2 upright fluorescence microscope (Carl Zeiss AG, Oberkochen, Germany).

Immunoblotting. Samples of cell lysates or nuclear fractions were separated by $12.5 \%$ SDS-PAGE and transferred onto a nitrocellulose membrane (GE Heakthcare, Taipei, Taiwan), as previously described (18). The blot was subsequently treated using standard procedures and probed with the following antibodies: c-Jun (cat.\#3270), c-Fos (cat. \#5348), phospho-FAK Tyr 925 (cat. \#3284), phospho-MEK1/2 (cat. \#9121), total-MEK1/2 (cat. \#9122), phospho-MLC-2 (cat. \#3671), total-MLC-2 (cat. \#3672), phospho-ERK1/2 (cat. \#9101), total-ERK1/2 (cat. \#9107) (1:1,000 dilution, monoclonal, Cell Signaling Technology, Inc., Danvers, MA, USA) and total-paxillin (cat. \#sc-136297), MMP-2 (cat. \#sc-13594), $\beta$-actin (cat. \#sc-10731), total-FAK (cat. \#sc-932) and C23 (cat. \#sc-17826) (1:1,000 dilution; monoclonal; Santa Cruz Biotechnology, Inc., Santa Cruz CA, USA) and phospho-paxillin Ser 178 (cat. \#44-1026; 1:1,000 dilution; monoclonal; Biosource, Camarillo, CA, USA). Protein expression was detected by chemiluminescence with an Enhanced Chemiluminescence Plus detection kit (Amersham Life Sciences, Inc., Piscataway, NJ, USA).

Measurement of lung metastasis in 786-O-SI3-bearing mice. Five-week-old male C57BL/6 mice (National Taiwan University Animal Center, Taiwan) were housed under a regular 12-h light/dark cycle and with ad libitum access to a standard rodent diet (Laboratory Rodent Diet 5001; LabDiet, St. Louis, MO). Cells $\left(1 \times 10^{6}\right)$ suspended in $0.1 \mathrm{ml}$ PBS were injected into the tail vein of the C57BL/6 mice. On the following day (day 1), the mice were randomly divided into three groups ( $\mathrm{n}=3$ for each group) to be fed by oral gavage with saline (control) or KFEE ( 0.1 and $0.2 \mathrm{~g} / \mathrm{kg}$ of body weight daily). Three untreated mice were used as wild-type controls. Following 31 days, the animals were sacrificed using $\mathrm{CO}_{2}$. The lungs were isolated and weighed, and metastatic nodules on the surface of the lungs were counted under a microscope (Axioskop 2 Plus, Carl Zeiss, Inc., Oberkochen, Germany). The lungs were fixed in neutral buffered 5\% formalin (Sigma), and sections were prepared and stained with hematoxylin and eosin (Sigma) for morphological studies (25).

Statistical analysis. Statistically significant differences throughout this study were calculated by Student's t-test (SigmaStat 2.0; Jandel Scientific, San Rafael, CA). $\mathrm{P}<0.05$ was considered to indicate a statistically significant difference between values.

\section{Results}

Polyphenol contents in KFEE. Quantitative analysis of phytochemicals revealed the presence of $38.8 \pm 0.4 \mathrm{mg} / \mathrm{g}$ polyphenols in KFEE. Reference compounds included gallic acid, gallocatechin, catechin, caffeic acid, rutin, naringin, quercetin, kaempferol, anthraquinone, myricetin, morin, apigenin and galangin (Fig. 1A and B). To evaluate the bioactive compounds in KFEE, K. formosana was successively extracted with $50 \%$ ethanol. HPLC analysis of KFEE (Fig. 1C) and 13 standard compounds showed peaks corresponding to the retention time chromatography and absorbance at $254 \mathrm{~nm}$. Gallic acid and caffeic acid were included in the composition of KFEE (Fig. 1D).

Xenograft-derived 786-O-SI3 cells display increased MMP-2. To determine whether the serial xenotransplantation of a cancer cell line in nude mice enriches the malignant subpopulation, tumor-forming 786-O cells were injected subcutaneously into the dorsal flank of five-week-old nude BALB/c nu/nu mice. Three xenograft-derived 786-O cell lines, namely 786-O-SI1, 786-O-SI2 and 786-O-SI3, were established from the xenograft tumors (Fig. 2A). 786-O-SI3 cells significantly exhibited increased MMP-2 activity compared to that of the control 786-O cell line ( $\mathrm{P}<0.001$; Fig. 2B), indicating that the successive implantation of 786-O cells in nude mice increased the ability of the tumor to metastasize. 
A

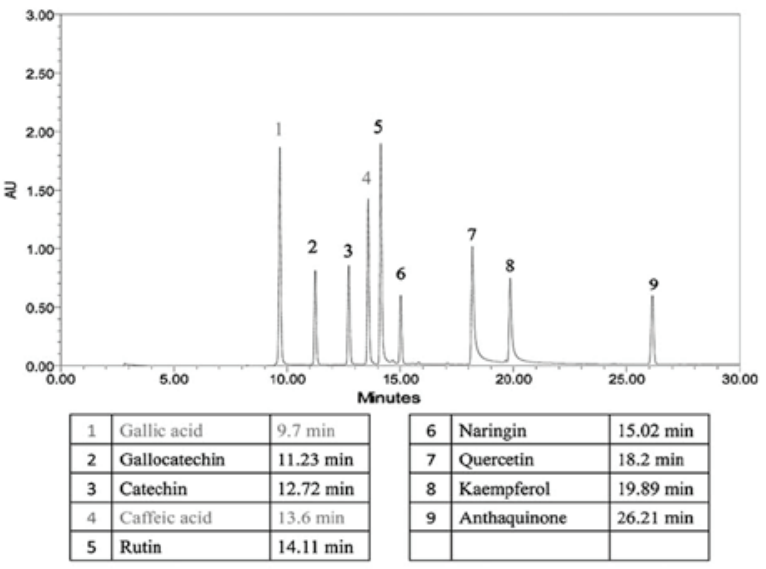

C

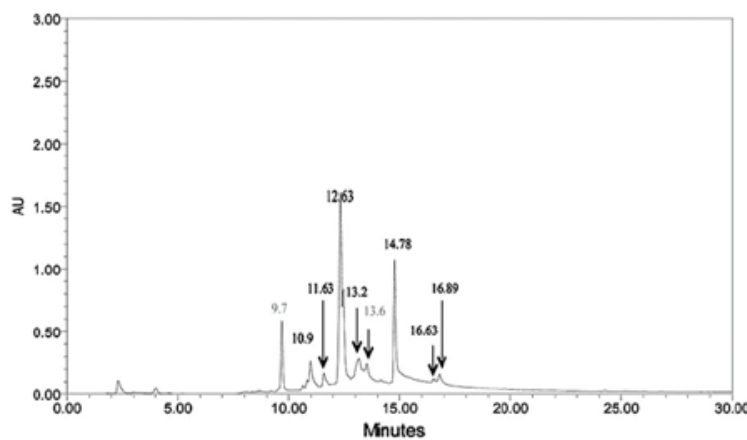

B

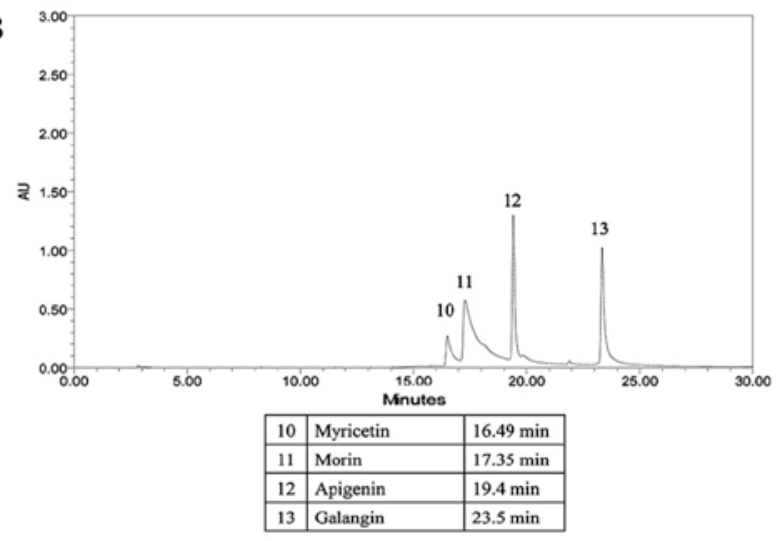

D

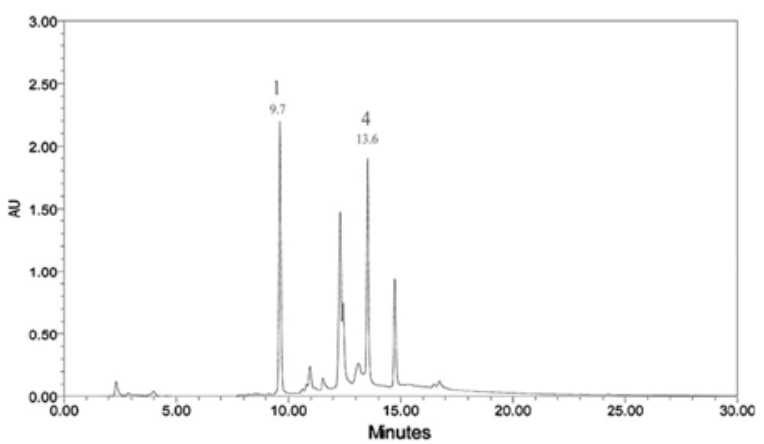

Figure 1. Chemical profile of KFEE analyzed by HPLC-mass spectrometry. (A) Chromatograms from HPLC analysis of KFEE showed peaks corresponding to the respective retention times (min) of the compounds. (B) HPLC chromatogram of nine standard compounds. Peaks: 1, 6.25 $\mu \mathrm{g}$ gallic acid; 2, $100 \mu \mathrm{g}$ gallocatechin; 3, $43.54 \mu \mathrm{g}(+)$ catechin; 4, $4.37 \mu \mathrm{g}$ caffeic acid; 5, 6.25 $\mu \mathrm{g}$ rutin; 6, $12.5 \mu \mathrm{g}$ naringin; 7, 3.77 $\mu \mathrm{g}$ quercetin; 8, 3.57 $\mu \mathrm{g}$ kaempferol; 9, 2.6 $\mu \mathrm{g}$ anthraquinone in $10 \mu \mathrm{gl} \mathrm{DMSO}$. (C) Peaks: 10,3.97 $\mu \mathrm{g}$ myricetin; 11, $9.96 \mu \mathrm{g}$ morin; 12, $6.7 \mu \mathrm{g}$ apigenin; 13, $0.24 \mu \mathrm{g}$ of galangin in $10 \mu 1$ DMSO. (D) Combination of $100 \mu \mathrm{g}$ of KFEE with two standard compounds, $6.25 \mu \mathrm{g}$ gallic acid and $4.37 \mu \mathrm{g}$ caffeic acid. Absorbance was monitored at $254 \mathrm{~nm}$. KFEE, Koelreuteria formosana ethanolic extract; HPLC, high-performance liquid chromatography; AU, absorbance units; DMSO, dimethyl sulfoxide..

A

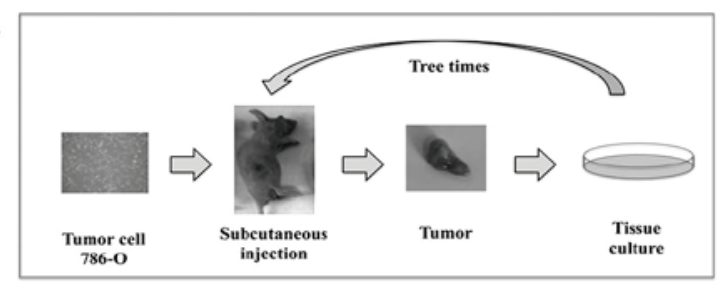

B

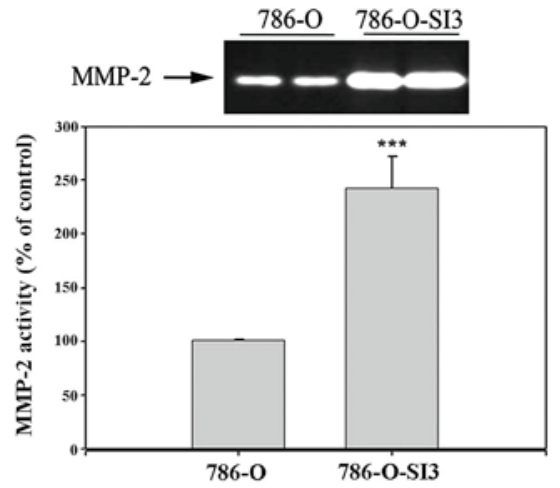

Figure 2. Primary culture and establishment of the 786-O-SI3 cell line. (A) The tumor xenograft was implanted as small tumor fragments into five-week-old BALB/c (nu/nu) mice. Growing tumors that reached a diameter of $\sim 1 \mathrm{~cm}$ were removed, smaller tumours were used for retransplantation and later used for the establishment of a cell line. (B) 786-O and 786-O-SI3 cell condition media were subjected to gelatin zymography to analyze the activity of MMP-2. Results were statistically evaluated using a one-way analysis of varience with Dunnett's post-hoc test $\left({ }^{* * * *} \mathrm{P}<0.001\right)$. MMP, matrix metalloproteinase.
Absence of cytotoxicity of KFEE on HK-2 cells and RCC 786-O-SI3 cells. A previous study reported no cytotoxic effects of KFEE $(\leq 100 \mu \mathrm{g} / \mathrm{ml})$ on RCC 786-O-SI3 cells (17). In the present study, RCC 786-O-SI3 and HK-2 cells were viable in the presence of $0,25,50,75$ and $100 \mu \mathrm{g} / \mathrm{ml}$ KFEE (Fig. 3A and B) ( $\mathrm{P}>0.05$ ). In all subsequent experiments, this concentration range was used for KFEE.

KFEE inhibits the invasion, motility and migration of RCC 786-O-SI3 cells. Incubation of 786-O-SI3 with $1 \% \mathrm{FBS}$ produced marked cell migration into the wounded area at 6 and 24 h following wounding, whereas wounds treated with KFEE showed significantly delayed wound healing under identical conditions (Fig. 3C and D). In addition, KFEE had a concentration-dependent inhibitory effect on cell migration, with $87.5 \pm 2.5 \%$ cell migration compared to that of the control $(\mathrm{P}<0.001)$ (Fig. $3 \mathrm{E}$ and $\mathrm{F})$. Under identical conditions, it was also observed that KFEE reduced the invasion of RCC 786-O-SI3 cells in a concentration-dependent manner, which was demonstrated using a cell invasion assay using a Matrigel-coated Boyden chamber. Following treatment with $100 \mu \mathrm{g} / \mathrm{ml} \mathrm{KFEE}$, invasion capability was decreased to $89.8 \pm 4.0 \%$ compared to that of the control $(\mathrm{P}<0.001)$ (Fig. 3E and $\mathrm{G})$.

KFEE suppresses the expression and activity of MMP-2 and $u$-PA in RCC 786-O-SI3 cells. To determine the involvement 

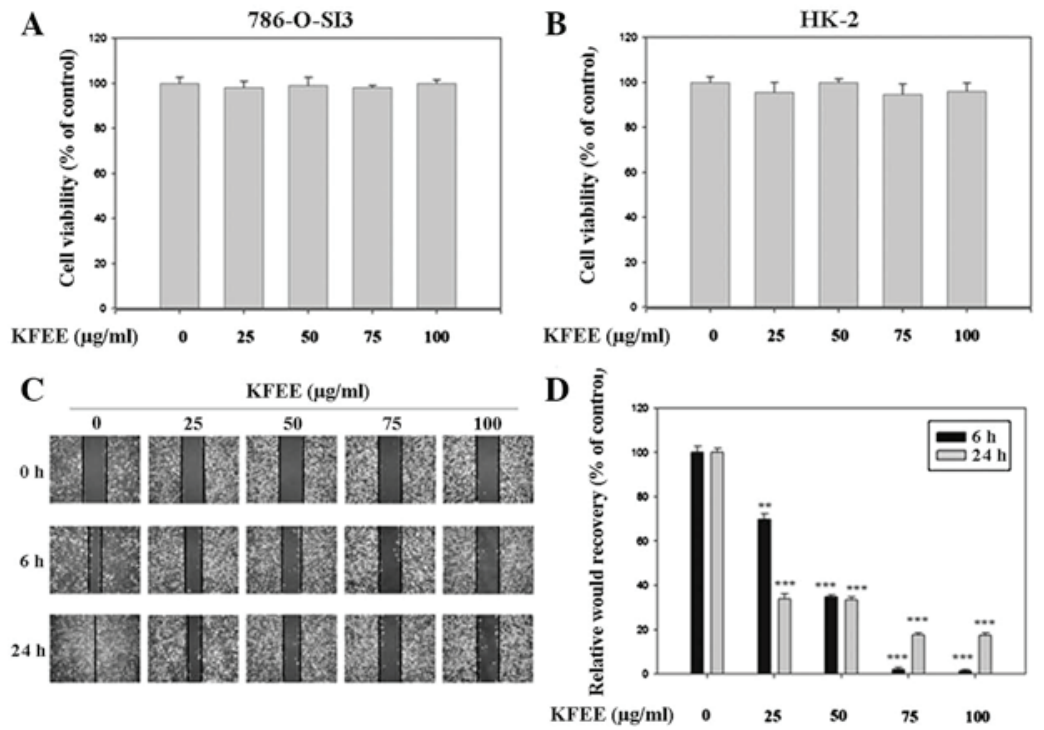

$\mathbf{E}$

Motility
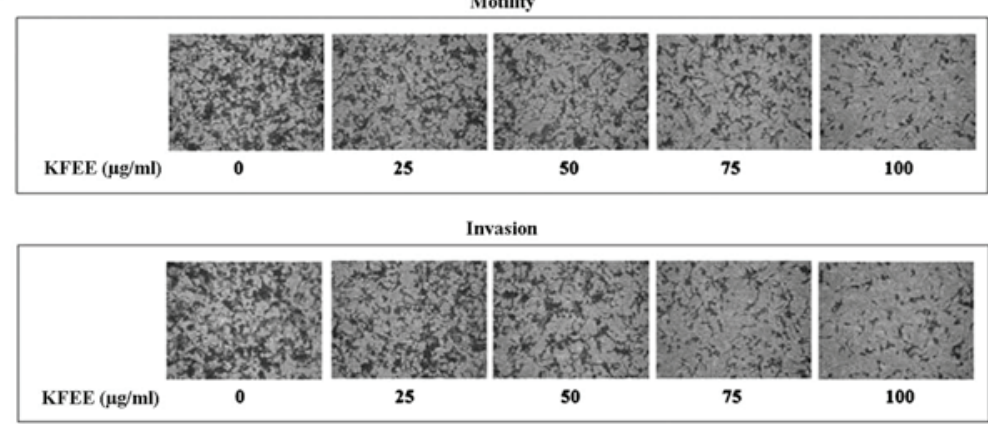

F

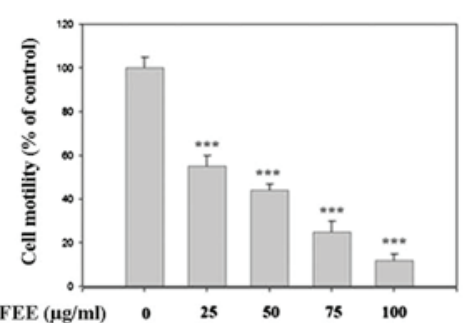

H
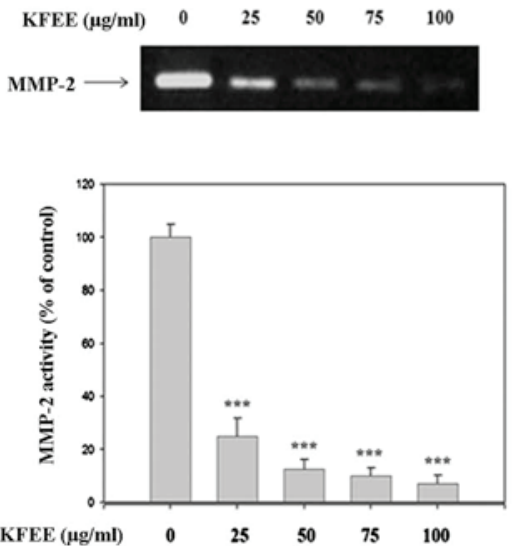

G

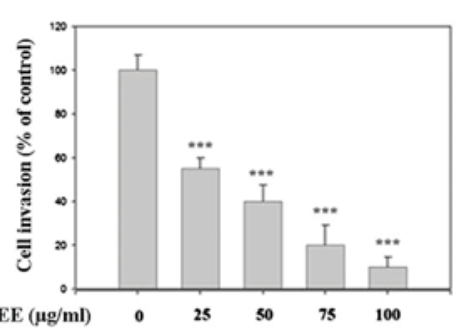

I
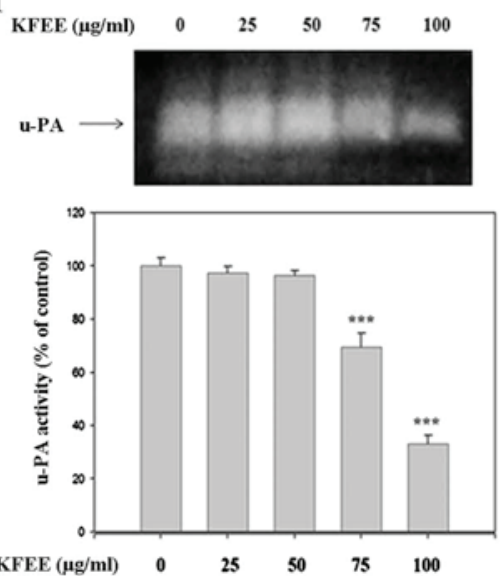

Figure 3. Effects of KFEE on cell viability, migration, motility and invasion of renal cell carcinoma. (A) 786-O-SI3 and (B) HK-2 cells were treated with KFEE using an MTT assay for $24 \mathrm{~h}$. (C) 786-O-SI3 cells were analyzed for cell migration using a wound healing assay (magnification, x100). (D) The determined migration ability of 786-O-SI3 was subsequently quantified as the percentage of the control (without KFEE for $24 \mathrm{~h}$ ). (E) Cells were treated with KFEE for $6 \mathrm{~h}$, then analyzed for motility and invasion (magnification, $\mathrm{x} 400$ ). (F and $\mathrm{G}$ ) Invasion and motility were quantified as the percentage of the control. 786-O-SI3 cells were treated with KFEE for $24 \mathrm{~h}$ and the condition media were subjected to gelatin zymography and casein zymography in order to analyze the activities of (H) MMP-2 and (I) u-PA. Results were statistically evaluated using a one-way analysis of variance with Dunnett's post-hoc test $\left(^{* *} \mathrm{P}<0.01\right.$; and ${ }^{* * *} \mathrm{P}<0.001$, compared with the control). Results were repeated three times and the separate experiments showed similar data. KFEE, Koelreuteria formosana ethanolic extract; MMP, matrix metalloproteinase; u-PA, urinary-type plasminogen activator. 


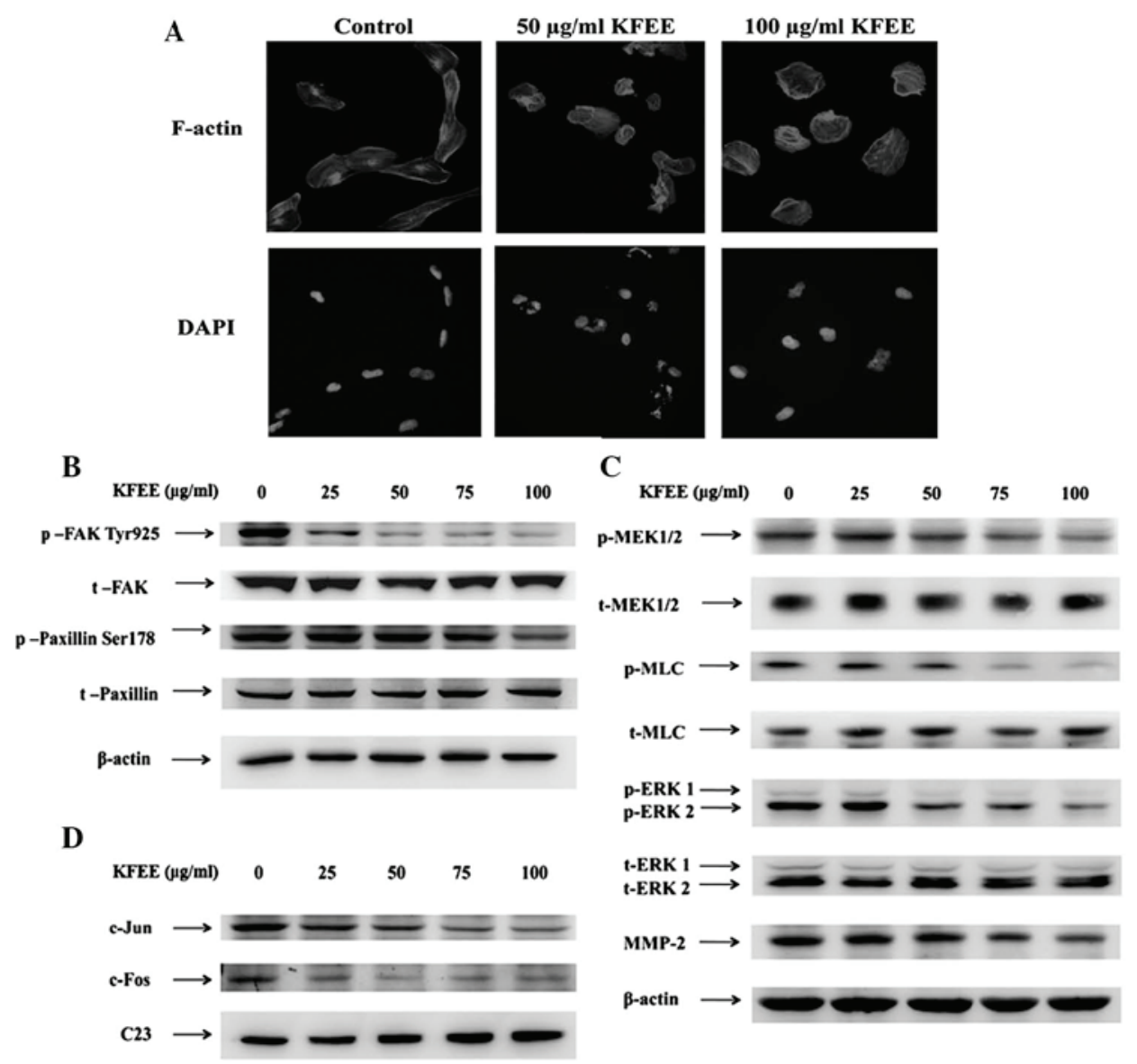

Figure 4. Effects of KFEE on the morphology of metastatic 786-O-SI3 cells and protein expression following induced Erk1/2 and MMP-2 activation. (A) Control and 50 or $100 \mu \mathrm{g} / \mathrm{ml} \mathrm{KFEE-treated} \mathrm{metastatic} \mathrm{786-O-SI3} \mathrm{cells} \mathrm{stained} \mathrm{with} \mathrm{phalloidin} \mathrm{to} \mathrm{detect} \mathrm{F-actin} \mathrm{(magnifaction,} \mathrm{x40).} \mathrm{Cell} \mathrm{lysates} \mathrm{were} \mathrm{sub-}$ jected to SDS-PAGE followed by western blot with (B) anti-phospho-FAK Tyr925, anti-phospho-Paxillin Ser178 and anti-GRB2; (C) anti-phospho-MEK1/2, anti-phospho-Erk1/2, anti-phospho-MLC Ser19 antibodies and anti-MMP-2; and (D) anti-c-Jun and anti-c-Fos antibodies with C23 as internal control. Protein signals were visualized using an enhanced chemiluminescence detection system. KFEE, Koelreuteria formosana ethanolic extract; Erk1/2, extracellular signal-regulated kinase 1/2; GRB2, growth factor receptor-bound protein 2; MMP, matrix metalloproteinase; FAK, focal adhesion kinase; MEK1/2, mitogen-activated protein kinase kinase 1/2; MLC, myosin light chain; $\mathrm{p}$, phosphorylated; $\mathrm{t}$, total.

of MMPs and u-PA in the KFEE-induced inhibition of invasion and migration of 786-O-SI3 RCC cells, the effects of KFEE on MMP and u-PA activity were investigated using gelatin and casein zymography, respectively, under serum-starved conditions. KFEE reduced the activity of MMP-2 $(\mathrm{P}<0.001)$ in gelatin zymography (Fig. $3 \mathrm{H})$ and that of $\mathrm{u}-\mathrm{PA}(\mathrm{P}<0.001)$ in casein zymography assays (Fig. 3I). Furthermore, KFEE decreased the migratory and invasive capacities of 786-O-SI3 cells and the cell shape changed from rounded to spindle-shaped, indicating that KFEE may regulate metastasis by controlling cytoskeletal events essential for motility (Fig. 4A).

KFEE decreases MMP-2 and inhibits the phosphorylation of focal adhesion kinase (FAK) Tyr925, mitogen-activated protein kinase kinase (MEK)1/2, extracellular-regulated kinase (Erk)1/2 and paxillin Ser178 in RCC 786-O-SI3 cells. Given that KFEE inhibited the invasion, migration and transcriptional levels of MMP-2 and u-PA activities in 786-O-SI3 cells, the effects of KFEE on the expression of the Erk1/2/mitogen-activated protein kinase (MAPK) pathways were investigated by western blot analysis to elucidate the underlying mechanisms. KFEE significantly inhibited phosphorylation of FAK Tyr925, Paxillin Ser178, MEK1/2 and
Erk1/2 (Figs. 4B and C) in RCC 786-O-SI3 cells. Therefore, inhibition of the FAK Tyr925 and Erk1/2 signaling pathways may be involved in the reduction of MMP-2 and u-PA activity, as well as tumor cell invasion. In contrast, the phosphorylation of myosin light chain (MLC)2 (Fig. 4C), the cell actin dynamic regulatory protein, was decreased.

KFEE decreases levels of c-Jun and c-Fos in RCC 786-O-SI3 cells. Western blot analysis revealed that KFEE significantly inhibited c-Jun and c-Fos levels in the nuclear extracts of RCC 786-O-SI3 cells ( $\mathrm{P}<0.001)$ (Fig. 4D).

KFEE inhibits lung colonization of 786-O-SI3 cells. 786-O-SI3 cells primarily form lung tumors. C57BL/6 mice were injected with $786-\mathrm{O}-\mathrm{SI} 3$ cells via the tail vein and administered either KFEE or saline via oral gavage. KFEE reduced 785-O-SI3 cell pulmonary metastasis formation. Within $31 \mathrm{~d}$ of injection, the average body weight of KFEE-treated mice was lower than that of the control group (Fig. 5A). The mean lung weights of animals receiving $0.1 \mathrm{~g} / \mathrm{kg} / \mathrm{d}$ KFEE $(0.4503 \pm 0.0838 \mathrm{~g} ; \mathrm{P}<0.001)$ and $0.2 \mathrm{~g} / \mathrm{kg} / \mathrm{d}$ KFEE $(0.3288 \pm 0.1208 \mathrm{~g} ; \mathrm{P}<0.001)$ were significantly lower than those of the control animals $(0.7154 \pm 0.0 .1601 \mathrm{~g}$; 

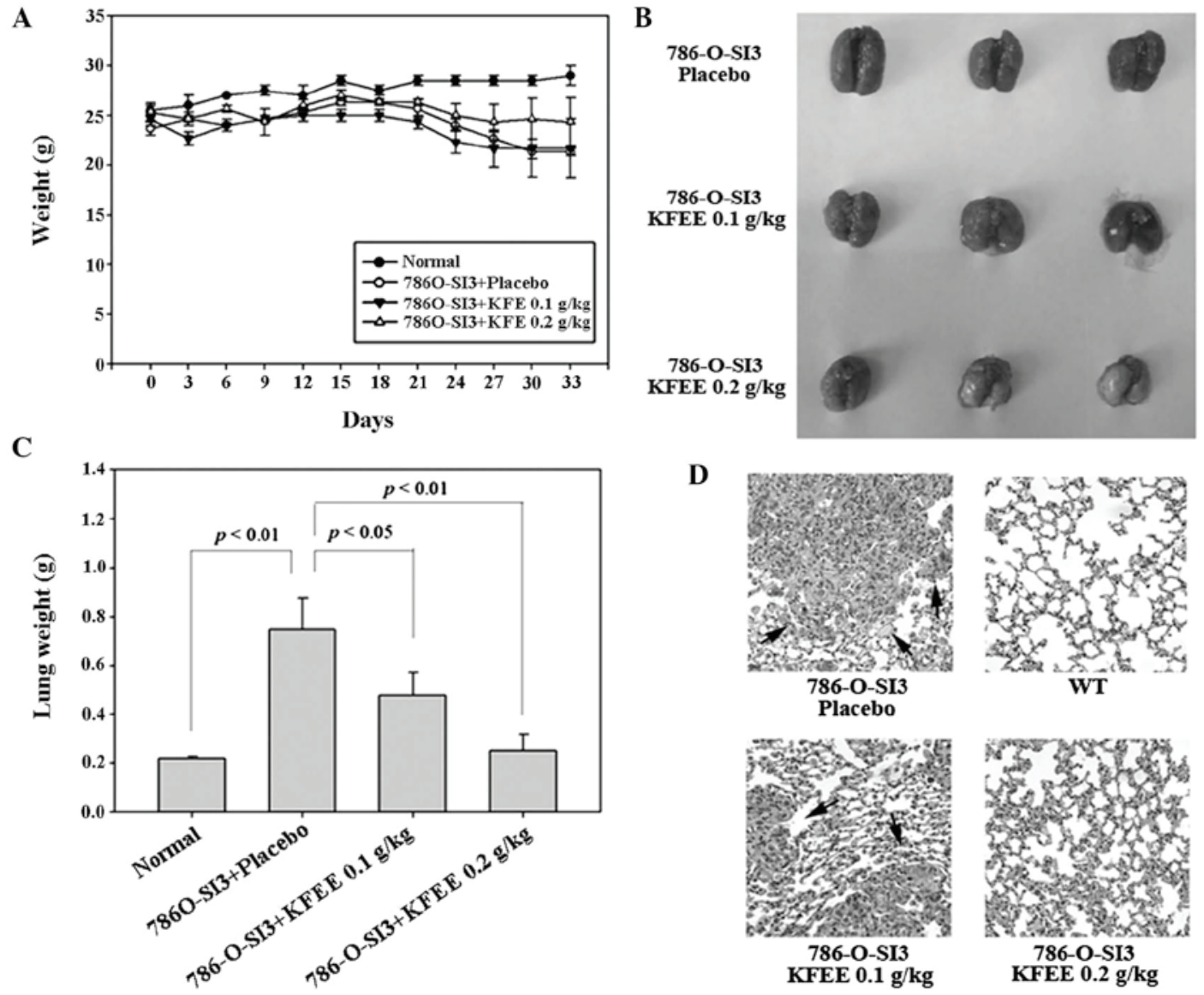

Figure 5. Suppression of metastatic renal cell carcinoma in mouse lungs by KFEE. 786-O-SI3 cells were injected into the tail veins of five-week-old male C57BL $/ 6$ mice. Following injection of 786-O-SI3 cells, KFEE $(0.1$ and $0.2 \mathrm{~g} / \mathrm{kg}$ ) and placebo (saline) were administered using an oral gavage for 31 days (A) Body weight of mice was measured every three days. Mice were sacrificed and their lungs were (B) compared using representative photographs of lungs and $(\mathrm{C})$ weighed. Results were statistically evaluated using a one-way analysis of variance with Dunnett's post-hoc test $\left({ }^{*} \mathrm{P}<0.05,{ }^{* * *} \mathrm{P}<0.01,{ }^{* * * *} \mathrm{P}<0.001\right)$. (D) Histopathology of the lungs of metastatic tumor-bearing C57BL/6 mice (magnification, x400). The lungs of metastasis-induced animals were fixed in neutral buffered formalin and stained with hematoxylin and eosin. Control (786-O-SI3 + placebo), normal lung (WT), 786-O-SI3 + 0.1 g/kg/d KFEE and 786-O-SI3 + 0.2 g/kg KFEE. KFEE, Arrows indicate tumor cells, as metastasis in the lung Koelreuteria formosana ethanolic extract; WT, wild type.

Fig. 5B). The lungs of the control mice were visibly riddled with metastatic tumor nodules compared with those of the KFEE-treated mice (Fig. 5C). Histopathology of the lung also showed marked reduction in tumor mass in the lungs of the KFEE-treated animals (Fig. 5D).

\section{Discussion}

A previous study demonstrated that KFEE inhibited human LDL and prevented oxLDL-induced apoptosis of human umbilical vein endothelial cells (13). The present study demonstrated the efficacy of KFEE as a therapeutic agent for RCC. KFEE decreased invasion and migration of RCC 786-O-SI 3 cells and reduced u-PA and MMP-2 expression. The mechanism of KFEE-induced downregulation of u-PA and MMP-2 activity was found to proceed via the inhibition of FAK Tyr925, Paxillin Ser178, MEK1/2 and Erk1/2 phosphorylation. Furthermore, histopathology of the lungs of C57BL/6 mice injected with RCC 786-O-SI3 cells showed a markedly reduced tumor mass in KFEE-treated animals, compared with that of the controls. In addition HPLC-mass spectrometry revealed that KFEE contained gallic acid and caffeic acid.
Gallic acid has been reported to inhibit melanoma and metastasis of gastric cancer cells $(26,27)$. Caffeic acid has been shown to inhibit the migration and invasion of oral cancer and hepatocarcinoma cells through inhibition of MMP-2 $(28,29)$. Serine proteases, metalloproteases and their inhibitors are known to be key enzymes in matrix remodeling during cancer invasion, migration and angiogenesis (30). MMPs and the plasminogen activation system crucially affect the process of cancer cell invasion and migration. In RCC, MMP-2, MMP-9 and u-PA are of prognostic significance (31-34).

The activation of one or more MAPK pathway signaling proteins (e.g. Erk1/2, c-Jun N-terminal kinase and p38) is necessary for the induction of MMP-2, MMP-9 and u-PA. Data from the present study showed that KFEE suppressed MMP-2 and u-PA activity in 786-O-SI3 cells by inhibiting the phosphorylation of FAK Tyr925, Paxillin Ser178, MEK1/2 and Erk 1/2. In addition, western blot analysis showed that KFEE inhibited the downstream effectors of the Erk1/2 pathway, c-Jun and c-Fos, in nuclear extracts. Gallic acid inhibits the invasion and migration of human prostate cancer cells and suppresses protein levels of MMP-2 and -9, FAK, JNK and ERK1/2 (35). The phosphorylation of paxillin Ser178 advances 
the association of paxillin with FAK, therefore inducing the migration of corneal epithelial cells (36).

RCC-bearing mice are well-established animal models for metastasis (37). In the present study, KFEE effectively inhibited numerous aspects of tumor formation in RCC 786-O-SI3 mouse models in vivo. This model was selected based on the aggressive behavior and the high metastatic potential of this RCC cell line. Following intravenous injection of RCC 786-O-SI3 cells, mice were treated by daily oral administration of KFEE and the results demonstrated that KFEE was able to significantly delay tumor cell colonization in the lungs of these mice.

In conclusion, the present study elucidated the anticancer mechanisms of KFEE. KFFE was shown to decrease levels of MMP-2, p-FAK try925, p-paxillin Ser178, p-MEK1/2, p-MLC and p-Erk1/2 in 786-0-SI3 cells. KFEE-treated mice also showed reduced lung metastases compared with those observed in vehicle-treated control mice. Overall, the results of the present study suggested that KFEE may be a potential therapeutic or adjuvant strategy for treating RCC patients. However, the clinical application of KFEE requires further investigation in terms of its molecular mechanisms and beneficial effects.

\section{Acknowledgements}

This study was supported by grants of National Science Council, Republic of China (nos. NSC 98-2313-B-166-004-MY3 and NSC 98-2313-B-040-004-MY3). Flow cytometry and confocal microscopy were performed at the Instrument Center of Chung Shan Medical University, supported by the National Science Council, Ministry of Education and Chung Shan Medical University.

\section{References}

1. Hutson TE and Quinn DI: Cytokine therapy: a standard of care for metastatic renal cell carcinoma? Clin Genitourin Cancer 4: 181-186, 2005.

2. Thoenes W, Störkel S and Rumpelt HJ: Histopathology and classification of renal cell tumors (adenomas, oncocytomas and carcinomas). The basic cytological and histopathological elements and their use for diagnostics. Pathol Res Pract 181: 125-143, 1986.

3. Al Otaibi M, Abou Youssif T, Alkhaldi A, Sircar K, Kassouf W, Aprikian A, Mulder D and Tanguay S: Renal cell carcinoma with inferior vena caval extention: impact of tumour extent on surgical outcome. BJU In 104: 1467-70, 2009.

4. Choueiri TK, Garcia JA, Elson P, Khasawneh M, Usman S, Golshayan AR, Baz RC, Wood L, Rini BI and Bukowski RM: Clinical factors associated with outcome in patients with metastatic clear-cell renal cell carcinoma treated with vascular endothelial growth factor-targeted therapy. Cancer 110: 543-550, 2007.

5. Amato RJ: Chemotherapy for renal cell carcinoma. Semin Oncol 27: 177-186, 2000.

6. Yagoda A, Abi-Rached B and Petrylak D: Chemotherapy for advanced renal-cell carcinoma: 1983-1993. Semin Oncol 22: 42-60, 1995 .

7. Cohen HT and McGovern FJ: Renal-cell carcinoma. N Engl J Med 353: 2477-2490, 2005.

8. Brugarolas J: Renal-cell carcinoma-molecular pathways and therapies. N Engl J Med 356: 185-187, 2007.

9. Athar U and Gentile TC: Treatment options for metastatic renal cell carcinoma: a review. Can J Urol 15: 3954-3966, 2008.

10. Liu YH, Li ML, Hsu MY et al: Effects of a Chinese herbal medicine, guan-jen-huang (Aeginetia Indica Linn.), on renal cancer cell growth and metastasis. Evid Based Complement Alternat Med 2012: 935860, 2012.
11. Wang SC, Tang SW, Lam SH et al: Aqueous extract of Paeonia suffruticosa inhibits migration and metastasis of renal cell carcinoma cells via suppressing VEGFR-3 pathway. Evid Based Complement Alternat Med 2012: 409823, 2012.

12. Lee SK, Jung HS, Eo WK, Lee SY, Kim SH and Shim BS: Rhus verniciflua Stokes extract as a potential option for treatment of metastatic renal cell carcinoma: report of two cases. Ann Oncol 21: 1383-1385, 2010.

13. Lin CY, Chen PN, Hsieh YS and Chu SC: Koelreuteria formosana extract impedes in vitro human LDL and prevents oxidised LDL induced apoptosis in human umbilical vein endo $\neg$ thelial cells. Food Chem 146: 299 307, 2014

14. Abou Shoer M, Ma GE, Li XH, Koonchanok NM, Geahlen RL and Chang CJ: Flavonoids from Koelreuteria henryi and other sources as protein tyrosine kinase inhibitors. J Nat Prod 56: 967 969, 1993

15. Chang CJ, Ashendel CL, Geahlen RL, McLaughlin JL and Waters DJ: Oncogene signal transduction inhibitors from medicinal plants. In Vivo 10: 185-190, 1996.

16. Lee TH, Chiang YH, Chen $\mathrm{CH}$, Chen PY and Lee CK: A new flavonol galloylrhamnoside and a new lignan glucoside from the leaves of Koelreuteria henryi Dummer. J Nat Med 63: 209-214, 2009.

17. Abou-Shoer M, Ma GE, Li XH, Koonchanok NM, Geahlen RL and Chang CJ: Flavonoids from Koelreuteria henryi and other sources as protein-tyrosine kinase inhibitors. J Nat Prod 56: 967-969, 1993.

18. Song YN, Zhang HL, Chang CJ and Bollag DM: Cytotoxic cyclolignans from Koelreuteria henryi. J Nat Prod 57: 1670-1674, 1994.

19. Chen $\mathrm{CH}$, Chan $\mathrm{HC}$ and $\mathrm{Chu} \mathrm{YT}$ et al: Antioxidant activity of some plant extracts towards xanthine oxidase, lipoxygenase and tyrosinase. Molecules 14: 2947-2958, 2009.

20. Lin CY, Chen PN, Hsieh YS and Chu SC: Koelreuteria formosana extract impedes in vitro human LDL and prevents oxidised LDL-induced apoptosis in human umbilical vein endothelial cells. Food Chem 146: 299-307, 2014.

21. Ho ML, Hsieh YS, Chen JY, Chen KS, Chen JJ, Kuo WH, Lin SJ and Chen PN: Antimetastatic potentials of Dioscorea nipponica on Melanoma in vitro and in vivo. Food Chem Toxicol 50: 558-66, 2012

22. Chu SC, Chiou HL, Chen PN, Yang SF and Hsieh YS: Silibinin inhibits the invasion of human lung cancer cells via decreased productions of urokinase-plasminogen activator and matrix metalloproteinase-2. Mol Carcinog 40: 143-149, 2004.

23. Chen PN, Hsieh YS, Chiang CL, Chiou HL, Yang SF and Chu SC: Silibinin inhibits invasion of oral cancer cells by suppressing the MAPK pathway. J Dent Res 85: 220-225, 2006.

24. Chu SC, Yang SF, Liu SJ, Kuo WH, Chang YZ and Hsieh YS: In vitro and in vivo antimetastatic effects of Terminalia catappa L. leaves on lung cancer cells. Food Chem Toxicol 45: 1194-1201, 2007.

25. Kim HJ, Kim YM, Lim S, et al: Ubiquitin C-terminal hydrolase-L1 is a key regulator of tumor cell invasion and metastasis. Oncogene 28: 117-127, 2009.

26. Lo C, Lai TY, Yang JS, et al: Gallic acid inhibits the migration and invasion of A375.S2 human melanoma cells through the inhibition of matrix metalloproteinase- 2 and Ras. Melanoma Res 21: 267-273, 2011.

27. Ho HH, Chang CS, Ho WC, Liao SY, Wu CH and Wang CJ: Anti-metastasis effects of gallic acid on gastric cancer cells involves inhibition of NF-kappaB activity and downregulation of PI3K/AKT/small GTPase signals. Food Chem Toxicol 48: 2508-2516, 2010

28. Peng CY, Yang HW, Chu YH, et al: Caffeic acid phenethyl ester inhibits oral cancer cell metastasis by regulating matrix metalloproteinase- 2 and the mitogen-activated protein kinase pathway. Evid Based Complement Alternat Med 2012: 732578, 2012.

29. Chung TW, Moon SK, Chang YC, et al: Novel and therapeutic effect of caffeic acid and caffeic acid phenyl ester on hepatocarcinoma cells: complete regression of hepatoma growth and metastasis by dual mechanism. FASEB J 18: 1670-1681, 2004.

30. Noel A, Maillard C, Rocks N, Jost M, Chabottaux V, Sounni NE, Maquoi E, Cataldo D and Foidart JM: Membrane associated proteases and their inhibitors in tumour angiogenesis. J Clin Pathol 57: 577-584, 2004

31. Kawata N, Nagane Y, Hirakata H, et al: Significant relationship of matrix metalloproteinase 9 with nuclear grade and prognostic impact of tissue inhibitor of metalloproteinase 2 for incidental clear cell renal cell carcinoma. Urology 69: 1049-1053, 2007. 
32. Takahashi M, Oka N, Naroda T, et al: Prognostic significance of matrix metalloproteinases- 2 activation ratio in renal cell carcinoma. Int J Urol 9: 531-538, 2002.

33. Harada K, Sakai I, Ishimura T, Inoue TA, Hara I and Miyake H: Clinical symptoms in localized renal cell carcinoma reflect its invasive potential: comparative study between incidentally detected and symptomatic diseases. Urol Oncol 24: 201-206, 2006.

34. Kallakury BV, Karikehalli S, Haholu A, Sheehan CE, Azumi N and Ross JS: Increased expression of matrix metalloproteinases 2 and 9 and tissue inhibitors of metalloproteinases 1 and 2 correlate with poor prognostic variables in renal cell carcinoma. Clin Cancer Res 7: 3113-3119, 2001.
35. Liu KC, Huang AC, Wu PP, et al: Gallic acid suppresses the migration and invasion of PC-3 human prostate cancer cells via inhibition of matrix metalloproteinase-2 and -9 signaling pathways. Oncol Rep 26: 177-184, 2011.

36. Huang Z, Yan DP and Ge BX: JNK regulates cell migration through promotion of tyrosine phosphorylation of paxillin. Cell Signal 20: 2002-2012, 2008.

37. Chang HR, Chen PN, Yang SF, et al: Silibinin inhibits the invasion and migration of renal carcinoma $786-\mathrm{O}$ cells in vitro, inhibits the growth of xenografts in vivo and enhances chemosensitivity to 5-fluorouracil and paclitaxel. Mol Carcinog 50: 811-823, 2011. 